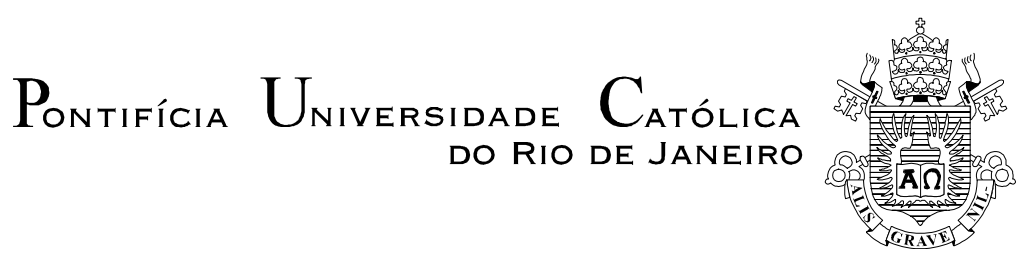

Marcos Vinicius Fiuza Coutinho

\title{
Entre memórias e palavras: o Neo-realismo de Manuel da Fonseca
}

\section{Tese de Doutorado}

Tese apresentada como requisito parcial para obtenção do grau de Doutor pelo programa de Pós-Graduação em Literatura, Cultura e Contemporaneidade do Departamento de Letras do Centro de Teologia e Ciências Humanas da PUC-Rio.

Orientador: Profa.Izabel Margato 


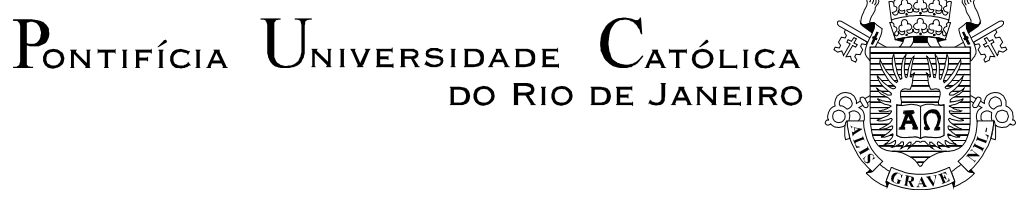

\section{Marcos Vinicius Fiuza Coutinho}

\section{Entre memórias e palavras: o neo- realismo de Manuel da Fonseca}

Defesa de Tese apresentada como requisito parcial para obtenção do grau de Doutor pelo Programa de PósGraduação em Literatura, Cultura e Contemporaneidade do Departamento de Letras do Centro de Teologia e Ciências Humanas da PUC-Rio. Aprovada pela Comissão Examinadora abaixo assinada.

Profa. Izabel Margato

Orientadora

Departamento de Letras - PUC-Rio

Prof. Paulo Roberto Tonani do Patrocínio Departamento de Letras - PUC-Rio- Colaborador

Prof. Alexandre Montaury Baptista Coutinho Departamento de Letras - PUC-Rio

Profa. Patricia Peterle Figueiredo Santurbano UFSC

Profa. Angela Maria Thereza Lopes UNESA

Prof. Ronaldo Menegaz PUC-Rio

Profa. Denise Berruezo Portinari Coordenadora Setorial do Centro de Teologia e Ciências Humanas - PUC-Rio

Rio de Janeiro, 11 de setembro de 2012. 
Todos os direitos reservados. É proibida a reprodução total ou parcial do trabalho sem autorização do autor, do orientador e da universidade.

\section{Marcos Vinicius Fiuza Coutinho}

Graduou-se em Letras pela UFRJ (Universidade Federal do Rio de Janeiro) em 2005. Possui especialização em Literaturas Portuguesa e Africanas pela mesma instituição (2007) e é mestre em Letras pela PUC-Rio.

Ficha catalográfica

Coutinho, Marcos Vinicius Fiuza

Entre memórias e palavras: o neo-realismo de Manuel da Fonseca ; orientador: Izabel Margato. $-2012$.

150 f. ; $30 \mathrm{~cm}$

Tese (doutorado)-Pontifícia Universidade Católica do Rio de Janeiro, Departamento de Letras, 2012.

Inclui bibliografia

1. Letras - Teses. 2. Neo-realismo português. 3. Fonseca, Manuel da. 4. Heterogeneidade estética. 5. Llirismo. I. Margato, Izabel. II. Pontifícia Universidade Católica do Rio de Janeiro. Departamento de Letras. III. Título.

CDD: 800 


\section{Agradecimentos}

À professora Izabel Margato pela confiança.

Ao professor Alexandre Montaury pelos conselhos e incentivos no inicio da caminhada.

À Capes e à PUC-Rio pelo apoio, sem o qual este trabalho não teria sido realizado.

A Fabiana, companheira de todas as horas.

A Vinícius Jatobá, parceiro de dúvidas e discussões.

A todos os funcionários do Departamento de Letras.

A todos os colegas da PUC-Rio. 


\section{Resumo}

Coutinho, Marcos Vinicius Fiuza; Margato, Izabel (Orientadora). Entre memórias e palavras: o Neo-realismo de Manuel da Fonseca. Rio de Janeiro, 2012. 150 p. Tese de Doutorado - Departamento de Letras, Pontifícia Universidade Católica do Rio de Janeiro.

Dentro do grande espectro de obras e escritores que constituem o Neorealismo português, é de fácil percepção que o movimento, em sua raiz, não se estabeleceu como uma estética uniforme. Apesar de uma linha marxista nortear claramente os caminhos e desígnios dos escritores, diferentes concepções e interpretações do que se deveria construir artisticamente se estabeleceu. Deparamo-nos com escritores muito singulares, que trabalham a temática, o pano de fundo neo-realista, de formas absolutamente distintas. A maneira como cada artista apreende a realidade e a reconsidera em suas obras é extremamente particular, fazendo da pesquisa em torno do que caracterizou o Neo-realismo uma enorme colcha de retalhos, em que, das diferentes e improváveis partes, retiramos um todo complexo e coeso. A forma como cada autor utiliza a palavra é, sem dúvida, o reflexo de como cada um deles interpreta a realidade. Nessa direção, pela maneira como as trabalha, utilizando uma precisão cirúrgica em cada vocábulo e ainda pela forma como introduz e engendra uma força vital a cada fato narrado, vemos destacar-se a figura de Manuel da Fonseca. Assim, este trabalho visa investigar, primordialmente, as estratégias de escrita desse autor, e, através do estudo de sua ficção, demonstrar como, a partir de personagens complexos, Manuel da Fonseca cria uma perspectiva que trabalha o ideal neo-realista de maneira extremamente particular e nos insere em um mundo de descobertas, onde o reconhecimento e o aprendizado são as chaves que possibilitam a abertura de uma zona de transformação eminente.

\section{Palavras-chave}

Neo-realismo português; Manuel da Fonseca; heterogeneidade estética; lirismo 


\section{Abstract}

Coutinho, Marcos Vinicius Fiuza; Margato, Izabel (Advisor). Between memories and words: The Neo-realism of Manuel da Fonseca. Rio de Janeiro, 2012. 150 p. PhD Thesis - Departamento de Letras, Pontifícia Universidade Católica do Rio de Janeiro.

Within the wide range of works and writers that make up the Portuguese Neo-Realism, is an easy to understand the movement, at its root, it has established itself as an aesthetic standard. Although a Marxist line guide clearly the ways and thoughts of the writers, different conceptions and interpretations of what we should build ourselves artistically. We face very unique writers, who work the theme, the background of neo-realist, absolutely distinct ways. The way each artist captures the reality and reconsiders in his works is very particular, doing research about what characterized the Neo-realism a huge patchwork quilt, in which the different and unlikely parts, removed a complex whole and cohesive . The way each author uses the word is undoubtedly a reflection of how each interprets reality. In this direction, by the way it works, using surgical precision in each word and also introduces the way and engenders a life force every event narrated, we highlight the figure of Manuel da Fonseca. This work aims to investigate primarily the writing strategies of the author, and, through the study of his fiction, showing how, from complex characters, Manuel da Fonseca creates a perspective that works the ideal neo-realist in an extremely and in particular enter into a world of discovery, where the recognition and learning are the keys that enable the opening of an imminent transformation zone.

\section{Keywords}

Neo-realism portuguese; Manuel da Fonseca; aesthetic diversity; lyricism 


\section{Sumário}

1 - APRESENTAÇÃO 09

PARTE I: O NEO-REALISMO E SEUS CONDICIONANTES 15

2-O Ambiente Sócio-político 16

2.1 - As duas primeiras décadas do século XX 17

2.2 - A década de 30 e a consolidação do Estado Novo 19

2.3 - O desenrolar das décadas 22

2.4 - O discurso do Estado Novo 25

3-O Ambiente Artístico 28

3.1 - Por entre modernismos: o establishment artístico 29

3.1.1 - $1^{\circ}$ modernismo português: a geração de Orpheu 30

3.1.2 - $2^{\circ}$ modernismo português: a geração de Presença 34

3.2 - Por entre polêmicas : o neo-realismo e a nova mundividência 39

3.2.1 - "Neo-realismos": a realidade em processo 49

3.2.2 - O neo-realismo e a dialética necessária 55

PARTE II: ENTRE MEMÓRIAS E PALAVRAS: O NEO-REALISMO DE 59 MANUEL DA FONSECA

$\begin{array}{ll}4 \text { - Primeiras palavras } & 60\end{array}$

5 - Memória e experiência: o processo de criação de Manuel da

$\begin{array}{ll}\text { Fonseca } & 62\end{array}$

6 - O conhecimento como percurso 81

7 - Entre espaços e paisagens 99

$\begin{array}{lr}7.1 \text { - Delimitando conceitos } & 100\end{array}$

7.2 - O homem e o espaço em Manuel da Fonseca 104

$\begin{array}{ll}8 \text { - Procedimentos de escrita } & 115\end{array}$

8.1 - Um breve panorama: da divisão platônica ao hibridismo do séc XX 118

$\begin{array}{ll}\text { 8.1.1 - A origem da divisão } & 118\end{array}$

8.1.2 - A força da forma: do pragmatismo horaciano à norma

$\begin{array}{ll}\text { renascentista } & 120\end{array}$

8.1.3 - A liberdade romântica 122

8.1.4 - O naturalismo de Brunetiere e a intuição de Croce 124

8.1.5 - A primeira metade do século $X X$ e a nova idéia de gênero 
literário

8.2 - O romance lírico e as marcas de Manuel da Fonseca

9 - Considerações finais

10 - Referências bibliográficas 